\title{
EUNIS 2013: Towards a Core Model for Higher Education IT Management Benchmarking
}

\author{
Janne Markus Juult ${ }^{1}$ \\ ${ }^{1}$ Aalto University School of Business, P.O. Box 21210, FI-00076 AALTO, janne.juult@aalto.fi \\ Keywords \\ Benchmarking, IT strategy.
}

\section{ABSTRACT}

This study evaluates three European higher education IT benchmarking projects by applying a custom comparison framework that is based on benchmarking literature and IT manager experience. The participating projects are Bencheit (Finland), UCISA (The United Kingdom) and UNIVERSITIC (Spain). EDUCAUSE (The United States of America) is also included as a project outside our geographical focus area due to its size and prominence in North America. Each of these projects is examined to map the data indicators they use and to form a rough description of their benchmarking process. Major components are then discussed to aid in the development of a European-wide higher education IT benchmarking model.

We found that the most common data indicators are related to costs, infrastructure, and IT management structure. Notable differences are related to the emphasis of common indicators, such as cost and infrastructure, as well as non-common indicators such as organisational learning and best practices. These differences seem to stem at least partially from the different goals of the projects.

The benchmarking processes have less variance than the data indicators. Some projects have more ambitious goals regarding organisational learning than others, which also had an impact on the data indicators. The most common tool to collect data from higher education institutions was to use a web-based form. Data analysis was most often done manually with Excel and often verified in a consistent process. All projects have a yearly cycle, and a yearly report for the participating organisations' managers was common.

\section{INTRODUCTION}

IT managers face a dilemma of comparing their institution's performance against others. It is not an inherently straightforward task, which is why benchmarking has been used as a tool to combat the problem. However, another problem arises when it becomes evident that existing benchmarking projects are geographically and jurisdictionally limited to their respective countries. Organisational differences in student and staff size, diversity of disciplines, amount and sources of funding are examples of features that make certain institutions unique within their respective countries.

Comparative surveys and benchmarking projects have been set up in different countries to map the practices in their respective Higher Education Institutions (HEl; universities, colleges, polytechnics and the like). These have provided data on a country-level basis, with metrics set by national standards. International comparison, however, is not as simple. Current national research data research projects are not directly comparable with each other. Differences in research methodology, term definitions and inherent styles of doing things further complicate comparative study.

The main objective is to study how comparable the national European IT benchmarking projects are and to find similarities between them to aid in the development of a large-scale European-wide IT benchmarking project. 


\section{COMPARISON FRAMEWORK}

The four projects have been examined through a two-trier framework that standardizes the comparison of data contents of these projects and their benchmarking process. The data portion is based on the views offered by the IT managers affiliated with Bencheit, and the process portion is based on a simplified version of the post-implementation IT benchmarking process by Doll, et al. (2003).

Table 1. Summary of the comparison framework components

\begin{tabular}{|l|l|}
\hline \multicolumn{1}{|c|}{ Data comparison framework } & \multicolumn{1}{c|}{ Process comparison framework } \\
\hline I. Indicator categorisation & I. Purpose and goals \\
\hline II. Personnel and students, amounts and costs & Il. Objects for benchmarking \\
\hline III. Infrastructure and hardware composition and costs & III. Outcomes and process attributes \\
\hline IV. Software composition and costs & IV. Data collection, verification, and reporting methods \\
\hline \multirow{2}{*}{ V. Distributed IT } & V. Level of comparison \\
\cline { 2 - 3 } & $\begin{array}{l}\text { Vl. The level of reported follow-up work and realised } \\
\text { benefits through benchmarking }\end{array}$ \\
\hline
\end{tabular}

It became evident that all the compared projects have a good grasp and solid experience on how to conduct the basic benchmarking. Their focus areas have some variance, and the differences in the educational sector are the main considerations that must be taken into account when building a common core model.

\section{CORE MODEL COMPONENTS}

We propose to start the common European benchmarking project through a Coordinating Organisation (CO). The participating individual projects would agree on a set of standards for key data indicators and their contents. This organisation would then collect the comparable data in specifically tailored modules from the individual participating projects, verify and analyse it, and finally present a common report for the individual projects. In a way the CO would act as a metabenchmarking project without the need of the individual projects to cease their operations.

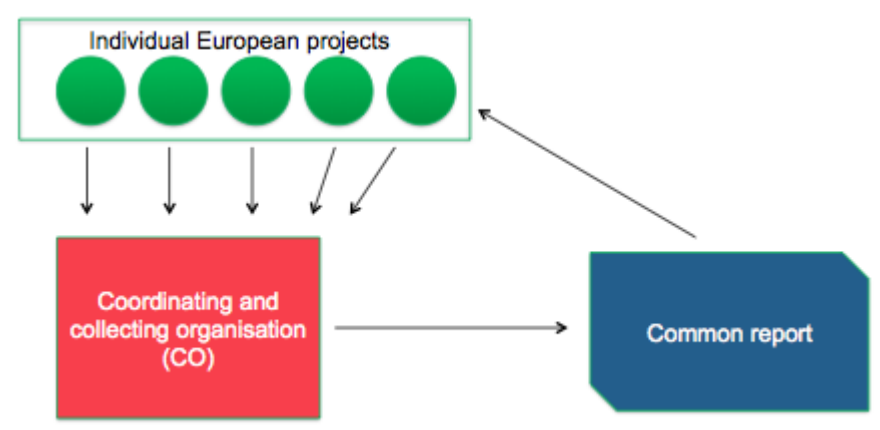

Organisational learning components play a prominent role in recent benchmarking theories. Traditionally these goals have been advanced through best practices, but there is a challenge to keep these practices agile as the benchmarking process continues yearly and is conducted in different environments. The practices must be kept broad enough to be successful.

Modularity was identified to be a successful trend in many benchmarking projects. This would probably be a good feature for the core model as well, since optional advanced modules would encourage HEls to participate even when their level of engagement varies. Additional countryspecific modules are also a possibility.

Funding options include at least modest participation fees, partner companies, and special funding from large organisations such as the European Union.

A common working language is an important step towards a unified model. The most natural choice for this would be English, the language of IT. The larger implications of this for a truly European project would warrant further research, however.

The structure of the core model is likely to be defined in more detail as the research advances further. 


\section{REFERENCES}

Bencheit (2013) http://www. bencheit.info (Accessed on 20.5.2013)

CRUE UNIVERSITIC (2013) http://www.crue.org/Publicaciones/universitic.html (Accessed on 20.5.2013)

Doll, W. J., Deng, X., \& Scazzero, J. a. (2003). A process for post-implementation IT benchmarking. Information \& Management, 41(2), 199-212. http://dx.doi.org/10.1016/S0378-7206(03)00048-X

EDUCAUSE Core Data Service (2013) http://www.educause.edu/research-andpublications/research/core-data-service (Accessed on 20.5.2013)

UCISA Best Practices (2013) http://www.ucisa.ac.uk/bestpractice.aspx (Accessed on 20.5.2013)

\section{ABOUT THE AUTHOR}

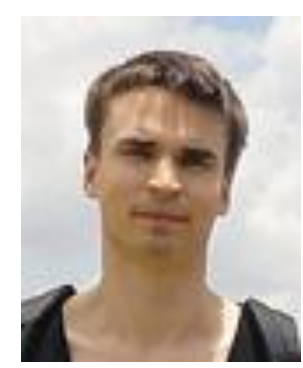

Janne Markus Juult is a Finnish graduate student in Aalto University School of Business and Université catholique de Louvain. With a dual interest in finance and information systems science, he has pursued a major in these two areas by balancing his studies between Finland and Belgium. After working in educational material imports, he has recently been introduced to the world of academia through research assistant position in Aalto University.

Interested in the enormous potential for combining IT and finance applications in developing countries, he uses most of his free time on traveling. He is currently based in Helsinki, Finland. 